\title{
Antipathetic Effect of Parthenium Hysterophorous on Staphylococcus Aureus
}

\author{
Versha Upadhyay \\ Department of Botany, Maya Group of Colleges, Dehradun (UK)
}

\begin{abstract}
Article Info

Volume 8, Issue 6

Page Number : 371-379

Publication Issue

November-December-2021

Article History

Accepted : 01 Dec 2021

Published : 12 Dec 2021

All the plants are medicinally beneficial for human beings, insect and microbes. Parthenium hysterophorus is weed. It has different type of secondary products and these all products are natural products. The natural plant products are used for the control of microorganisms causing plant and human diseases. The effect of plant extracts was 25\% - 2.66, 50\%-5.33, 70\% - 6.00 and $100 \%-7.33$ respectively, but in controlled hole no inhibition zone.

Keywords : Parthenium hysterophorus, secondary products, microorganisms, medicines.
\end{abstract}

\section{INTRODUCTION}

Medicinal plants have played an essential role in the development of human culture, for example religions and different ceremonies. (eg. Dhatura has long been associated with the worship of Shiva, Indian God). Durba grass (Cynodon dactylon) is believed to have a purifying effect on participants and is used as an offering in Ganesha Temples.

Ever since ancient times, in search for rescue for their diseases, the people looked for drugs in nature. In view of the fact that at the time there was not sufficient information either concerning the reasons for the illnesses or concerning which plant and how it could be utilized as a cure, everything was based on experience. In time, the reasons for the usage of specific medicinal plants for treatment of certain diseases were being discovered; thus, the medicinal plants' usage gradually abandoned the empiric framework and became founded on explicatory facts.

The use of plant compounds to treat infection is an age old practice in a large part of the world, especially in developing countries, where there is dependence on traditional medicine for a variety of diseases. In recent years attention has been given to natural systems of treatment for protection and management against pathogens. Plant extracts have played an important role in the inhibition of pathogens and it improve the quality and yield of food products. The use of plant extracts with known antimicrobial properties can easily treat the diseases. A wide variety of medicinal plants used traditionally have not yet been systematically investigated against various microbial pathogens (Aqil and Ahmad, 2003). Parthenium weed is used to treat wounds, diabetes, ulcerated sores, fever, diarrhea, anemia, heart troubles, malaria, headache, 
inflammatory, urinary infections, skin rashes, neurological disorder, and female reproductive problems. This can be related to the fact that parthenium produces secondary plant metabolite chemicals with potent antimicrobial activity (Veena \& Shivani 2012).

Resistance to antimicrobial agents is a major global health problem and the number of emerging multidrug resistant microbial is continuously increasing. This situation has promoted researchers to develop efficient new antimicrobial agent (Ashwini and Girish; 2014). In place of synthetic drugs antimicrobials of plant origin have a great therapeutic potential to heal many infectious disease and does not any side effect. It is observed that single antibiotic may not produce the desired inhibitory effects to certain disease and cure. To overcome this, combination of drugs with their synergistic effect, becomes more effective in the inhibition of a particular species of micro-organisms. (Sumitra Chandra et.al. 2011).

Traditional medicine is one of the most in expensive and easily accessible source of treatment in the health care. In recent years research for new drug discoveries using natural products has been increased. The natural plant products, known as botanical pesticides or herbal medicines, have long been used in the control of microorganisms causing plant and human diseases. The use of plant compounds to treat infection is an age- old practice in a large part of the world, especially in developing countries, where there is dependence on traditional medicine for a variety of diseases. Plant extracts have played significant role in the inhibition of pathogens and in the improvement of quality and yield of food. Infectious diseases are the world's leading cause of premature deaths, killing almost 50,000 people every day. In recent years drug resistance to human pathogenic bacteria has been commonly reported from all over the world (Singh et.al., 1992, Mulligen 1993).

\section{METHODS PLANT MATERIAL}

The leaves of plant Parthenium hysterophorus were taxonomically identified from Botanical Survey of India, Dehradun, India. Fresh and mature leaves, of Parthenium hysterophorus were collected from the nearest place of Maya group of College, Dehradun. Then fresh leaves of the plants were air dried at room temperature before grinding them to powder form with the help of mechanical grinder. $25 \mathrm{~g}$ of the air dried powder of each of leaves, powder were filled in the thimble and extracted successively with $300 \mathrm{ml}$ of methanol using a Soxhlet extractor for $72 \mathrm{~h}$. Each extract was first filtered using Whatman No.1 filter paper. The filtrate material was evaporated under reduced pressure in vacuum evaporator for crud extraction. The dried crude extracts were sterilized overnight by UV radiation and stored at room temperature in amber color glass vials until used for antibacterial testing (Boukhris et al., 2013).

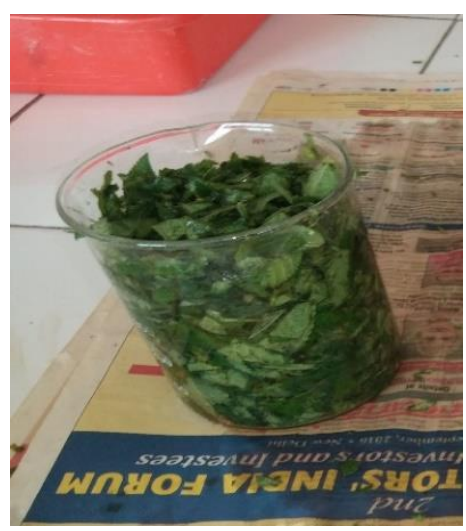

Fig.1. Methanolic Plant Extract

\section{For antibacterial activity,}

Nutrient agar medium (NAM).

Inoculum of the microbes: The bacterial cultures used for the study is

Staphylococcus aureus inoculated into separately at $30^{\circ} \mathrm{C}$ for $24 \mathrm{~h}$. The suspension was checked to provide approximately, $108 \mathrm{CFU} / \mathrm{ml}$. To the determination in diameter of zone of inhibition examined by well diffusion method (Mounyr, et.al.2016). The inoculation of bacteria in culture medium. A total of $8 \mathrm{~mm}$ diameter wells were 
punched into the agar and filled with leaves extracts $(250 \mu \mathrm{g} / \mathrm{ml})$. The plates were kept at $30^{\circ} \mathrm{C}$ for $24 \mathrm{~h}$ for determination of antibacterial activity of the extracts and solvent blank. The procedure for the examination of antibacterial activity was performed in triplicates to confirm the readings of diameter of zone of inhibition observed for each of the test organism.

\section{BACTERIAL STRAIN}

Morphology of bacteria

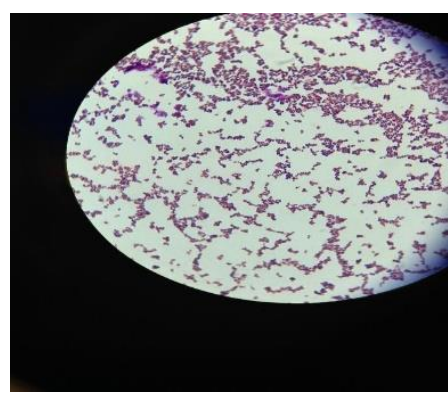

Figure 2. Strain of S.aureus.

$S$. aureus can cause a range of illnesses, from minor skin infections, such as pimples, impetigo, boils, cellulitis, folliculitis, carbuncles, scalded skin syndrome, and abscesses, to life-threatening diseases such as pneumonia, meningitis, osteomyelitis, endocarditis, toxic shock syndrome, bacteremia, and sepsis. It is still one of the five most common causes of hospital-acquired infections and is often the cause of wound infections following surgery (Singh, et.al. 2018). S. aureus is not always pathogenic, it is a common cause of skin infections including abscesses, respiratory infections such as sinusitis, and food poisoning. The emergence of antibiotic-resistant strains of $S$. aureus such as methicillin-resistant $S$. aureus is a worldwide problem in clinical medicine. Despite much research and development there is no approved vaccine for $S$. aureus (Tracey et.al. 2018)

\section{MICRODILUTION METHOD PRINCIPLE :}

Dilution susceptibility testing methods are used to determine the minimal concentration of antimicrobial needed to inhibit or kill the microorganism. This can be achieved by dilution of antimicrobial in either agar or broth media (Vineetha et. al. 2015).

\section{AGAR WELL DIFFUSION METHOD}

PRINCIPLE : The antimicrobials present in the plant extract are allowed to diffuse

out into the medium and interact in a plate freshly seeded with the test organisms. The resulting zones of inhibition will be uniformly circular as there will be a confluent lawn of growth. The diameter of zone of inhibition can be measured in millimeters.

Plate showing wells made with borer procedure Petriplates containing 20ml Muller Hinton medium were seeded with $24 \mathrm{hr}$ culture of bacterial strains. A sterile stick was used to spread about $0.2 \mathrm{ml}$ of the standardized test inoculum evenly on the surface of the solidified media. Five equidistant wells of $5 \mathrm{~mm}$ in diameter were then made on the seeded agar plate using a sterile cork borer and the plant extracts with concentrations ranging from 25\%, 50\%, 70\% and $100 \%$ respectively, were introduced into the bored holes. A $5 \mathrm{ml}$ of tween 20 was used in reconstituting the extracts. The plates were then incubated at $37^{\circ} \mathrm{C}$ for 24 hours. The antibacterial activity was assayed by measuring the diameter of the inhibition zone formed around the well (NCCLS, 1993).

\section{MICROORGANISMS}

Microorganisms (or microbes for short) play a very important role in our lives. Some microbes cause disease but the majority is completely harmless. In fact we couldn't live without them, but they could live without us.These microscopic organisms play a key role in maintaining life on earth, fixing gases and breaking down dead plant and animal matter into simpler substances that are used at the beginning of the food chain.

Microbes are very small living organisms, so small that most of them are invisible. The majority can only be seen with a microscope, which magnifies their image so we can see them. In fact microbes are so tiny you would find over a million in a teaspoon of soil. They make up more than $60 \%$ of the Earth's living 
matter and scientists estimate that 2-3 billion species share the planet with us.

Muzafar Sheikh et.al., (2012) worked to check the antimicrobial potential of eleven different aqueous leaf extracts on Xanthomonas campestris, Agrobacterium rhizogenesand Aspergillus fumigates based on formation of the zone of inhibition (ZOI). Statistical analysis (ANOVA followed by LSD P = 0.05 ) of the data on antifungal activity of aqueous extract of eleven plant species and two antibiotics on Aspergillus fumigates indicate that ZOI formed around aqueous extract of Prosopis juliflora and Ageratum conyzoides leaves were significantly high in comparison to that of Hyptis suaveolens and Jatropha gossypi folia. In the pre-sent study the evaluation of antimicrobial activity of aqueous plant extracts was based on formation of zone of inhibition around the $5 \mathrm{~mm}$ well on the Petri dishes filled with nutrient media and smeared with test pathogens. No doubt this piece of work seems to be ordinary, but in real sense this study can help us in achieving the target aim to reduce or to eradicate the target pathogens in an eco-friendly way, furthermore the leaf extracts were obtained from mostly weeds, weeds are unwanted plants out of place, so we have tried to obtain the target aim by mixing the plant extracts in water, that too is not a costly approach and the results are satisfactory Staphylococcus aureus

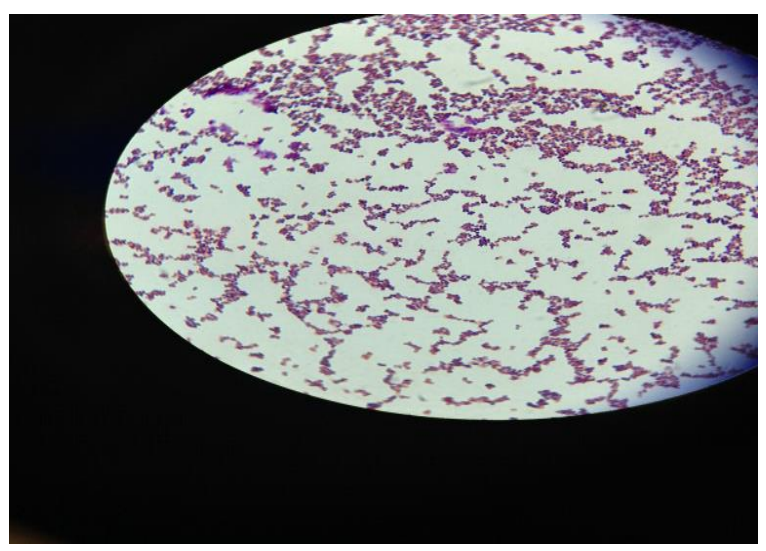

Figure 3. Strain of S.aureus.

Staphylococcus aureus is a gram-positive, roundshaped bacterium that is a member of the
Firmicutes, and is frequently found in the nose, respiratory tract, and on the skin. It is often positive for catalase and nitrate reduction and is a facultative anaerobe that can grow without the need for oxygen. Although S. aureus is not always pathogenic, it is a common cause of skin infections including abscesses, respiratory infections such as sinusitis, and food poisoning. Pathogenic strains often promote infections by producing virulence factors such as were collected potent protein toxins, and the expression of a cell-surface protein that binds and inactivates antibodies. The emergence of antibiotic-resistant strains of $\mathrm{S}$. aureus such as methicillin-resistant S. aureus (MRSA) is a worldwide problem in clinical medicine. Despite much research and development there is no approved vaccine for $\mathrm{S}$. aureus.

\section{Method}

The plant material was washed gently with Tin twenty to remove any dirt and to free it from any microbe and was air-dried under shade for a week. The sample was powdered with an electric grinder into a coarse form and stored in airtight containers.

\begin{tabular}{|l|l|l|}
\hline \multicolumn{1}{|c|}{$\begin{array}{c}\text { Plant } \\
\text { Material }\end{array}$} & \multicolumn{1}{|c|}{$\begin{array}{c}\text { Fresh } \\
\text { weight }\end{array}$} & $\begin{array}{c}\text { Dried } \\
\text { weight }\end{array}$ \\
\hline $\begin{array}{l}\text { P. hysterophorus } \\
\text { L. }\end{array}$ & 500 grams & 150 grams \\
\hline
\end{tabular}

Table - 1 Plant material weight

After grinding, $30 \mathrm{gm}$ of plant material was extracted in $130 \mathrm{ml}$ of methanol for 24 hours. The extracts were filtered through Whatmman filter paper and were evaporated to dryness using a hot plate at a much reduced temperature $\left(40^{\circ} \mathrm{C}\right)$. The residues obtained were dissolved in methanol. The weights of the extract was determined and stored below ambient temperature. 


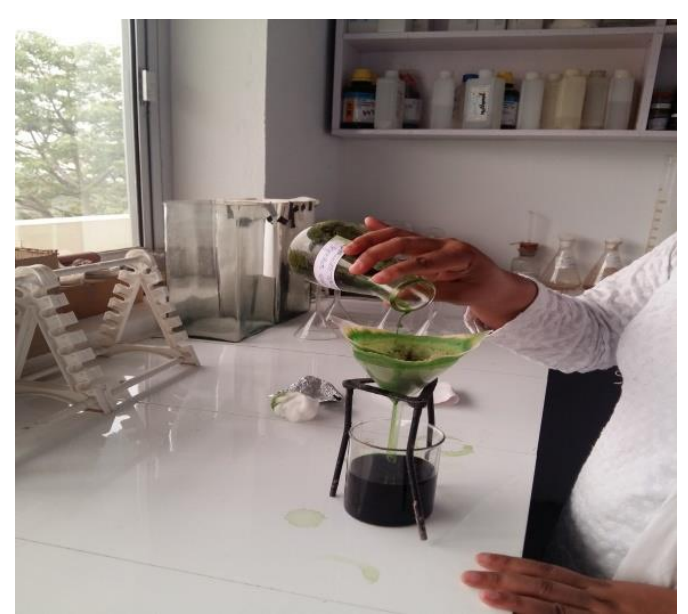

(a)

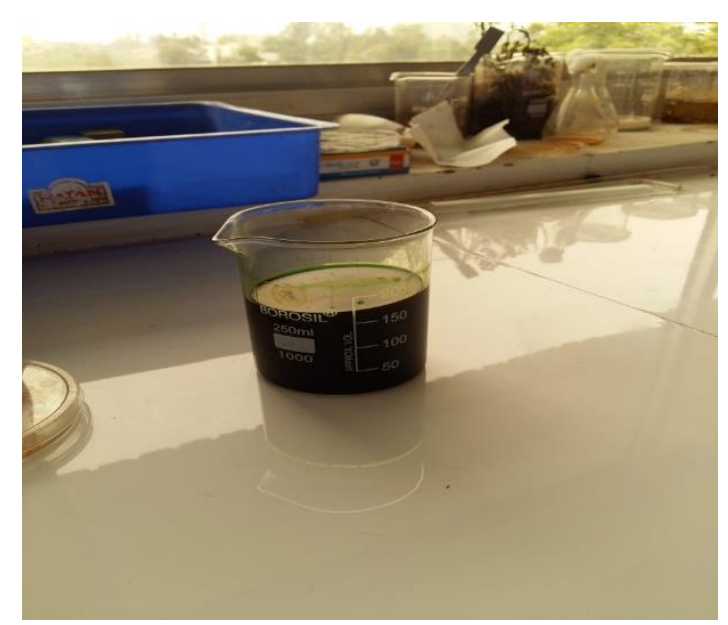

(b)

Fig4 (a) preparation of crude methanolic extract

(b) Methanolic extract of plant (green in colour)

\section{Culture collection and maintenance}

Strains of Staphylococcus aureus was used for the study of antibacterial activity. These standard strain was prepared in microbiology laboratory of Maya Group of Colleges, Dehradun.

\section{REAGENTS}

\section{Muller Hinton Agar Medium ( $250 \mathrm{ml})$}

The medium was prepared by dissolving $19.5 \mathrm{~g}$ of the commercially available Muller Hinton Agar Medium (Hi Media) in $250 \mathrm{ml}$ of distilled water. The dissolved medium was autoclaved at $15 \mathrm{lbs}$ pressure at $121^{\circ} \mathrm{C}$ for 15 minutes. The autoclaved medium was mixed well and poured onto 10 plates petriplates ( $25-30 \mathrm{ml} /$ plate) while still molten.

\section{Nutrient broth $(50 \mathrm{ml}))$}

$50 \mathrm{ml}$ of nutrient broth was prepared by dissolving $0.25 \mathrm{~g}$ beef extract, $0.25 \mathrm{~g}$ Peptone, $0.15 \mathrm{~g}$ Nacl in $50 \mathrm{ml}$ distilled water and boiled to dissolve the medium completely. The medium was dispensed as desired and sterilized by autoclaving at 15 lbs pressure $\left(121^{\circ} \mathrm{C}\right)$ for 15 minutes.

\section{MICRODILUTION METHOD PRINCIPLE}

Dilution susceptibility testing methods are used to determine the minimal concentration of antimicrobial needed to inhibit or kill the microorganism. This can be achieved by dilution of antimicrobial in either agar or broth media. Antimicrobials are tested in $\log _{2}$ serial dilutions (two fold).

\section{PROCEDURE}

The minimum inhibitory concentration (MIC) was determined by micro dilution method using serially diluted plant extracts. The methanol extract were diluted to get series of concentrations from $25 \%, 50 \%, 75 \%$ and $100 \%$ respectively in distilled water. The microorganism suspension of $50 \mu$ l was added to the broth dilutions. These were incubated for 18 hours at $37^{\circ} \mathrm{C}$. MIC of each extract was taken as the lowest concentration that did not give any visible bacterial growth. (E. L. Chuah 2014).

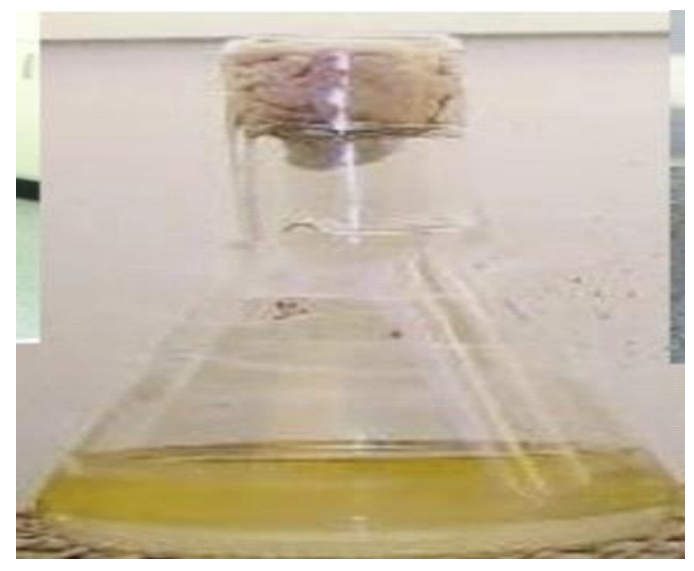

(a) 


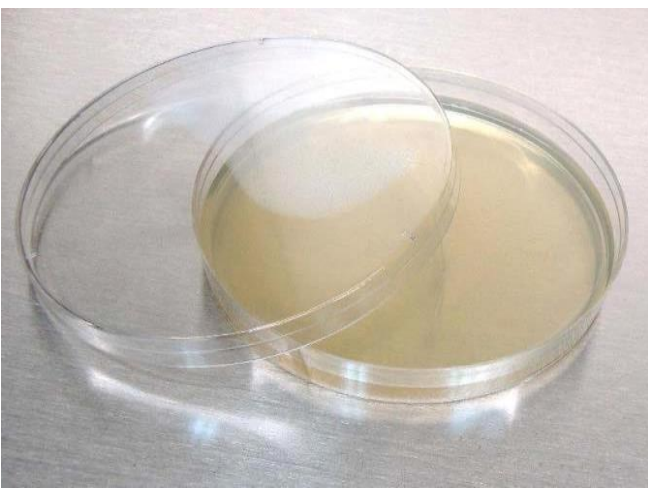

(b)

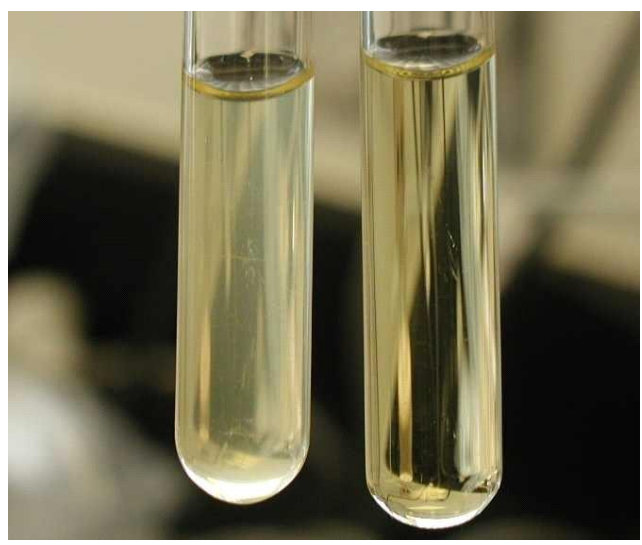

(c)

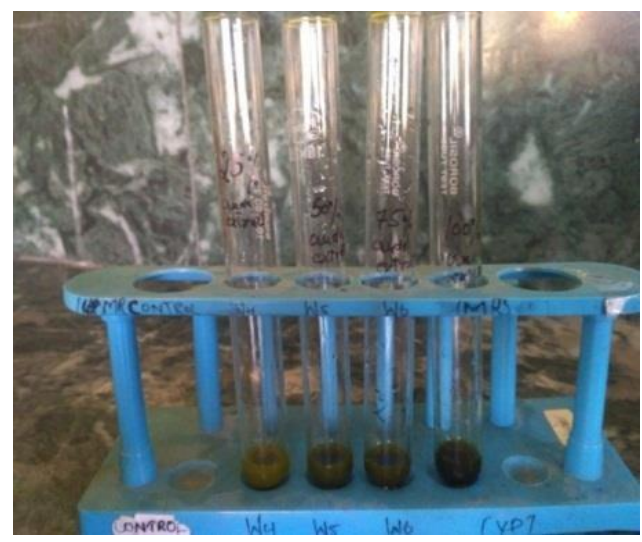

(d)

Fig. 5. (a) MHA (250ml), (b) MHA Plate, (C) Nutrient broth, (d) Test tubes containing crude methanolic extract of $P$. hysterophorus with different concentrations

Evaluation of antibacterial activity. The effect of various plant extracts on the several bacterial strains were assayed by Agar well diffusion method and further confirmed

by disc diffusion method. The minimum concentrations of the plant extracts to inhibit the microorganisms were also determined by micro dilution method using

plant fractions serially diluted in sterile nutrient broth. Bacterial cultures of that were used for antimicrobial assay of test organisms were obtained from the culture

Collection, Maya Group of Colleges, Dehradun. The bacteria were maintained on nutrient broth (NB) at $37^{\circ} \mathrm{C}$ till required for analysis.

\section{Evaluation of antibacterial activity}

The effect of various plant extracts on the several bacterial strains were assayed by Agar well diffusion method and further confirmed by Disc diffusion method. The minimum concentrations of the plant extracts to inhibit the microorganisms were also determined by micro dilution method using plant fractions serially diluted in sterile nutrient broth. Bacterial cultures of that were used for antimicrobial assay of test organisms were obtained from the culture collection, Department of Microbiology, Maya Group of Colleges, Dehradun. The bacteria were maintained on nutrient broth (NB) at $37^{\circ} \mathrm{C}$ till required for analysis.

\section{AGAR WELL DIFFUSION METHOD PRINCIPLE}

The antimicrobials present in the plant extract are allowed to diffuse out into the medium and interact in a plate freshly seeded with the test organisms. The resulting zones of inhibition will be uniformly circular as there will be a confluent lawn of growth. The diameter of zone of inhibition can be measured in millimeters.

\section{PROCEDURE}

Petriplates containing 20ml Muller Hinton medium were seeded with $24 \mathrm{hr}$ culture of bacterial strains. A sterile swab stick was used to spread about $0.2 \mathrm{ml}$ of the standardized test inoculum evenly on the surface of the solidified media. Five equidistant wells of $5 \mathrm{~mm}$ 
in diameter were then made on the seeded agar plate using a sterile cork borer and the plant extracts with concentrations ranging from $25 \%, 50 \%, 70 \%$ and $100 \%$ respectively, were introduced into the bored holes. A $5 \mathrm{ml}$ of tween 20 was used in reconstituting the extracts. The plates were then incubated at $37^{\circ} \mathrm{C}$ for 24 hours. The antibacterial activity was assayed by measuring the diameter of the inhibition zone formed around the well (NCCLS, 1993).

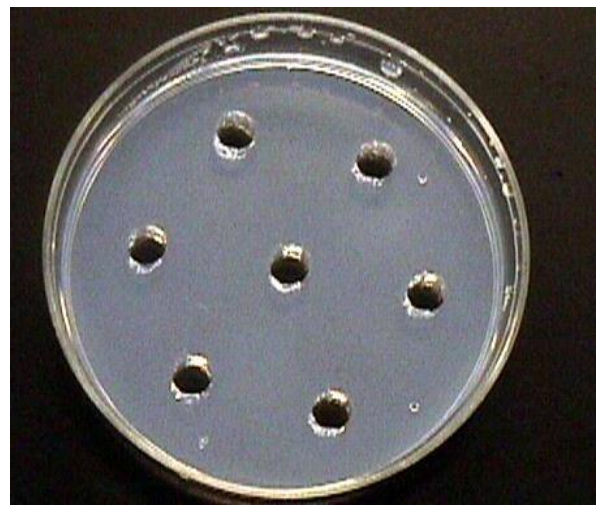

Fig.6. Plate showing wells made with borer

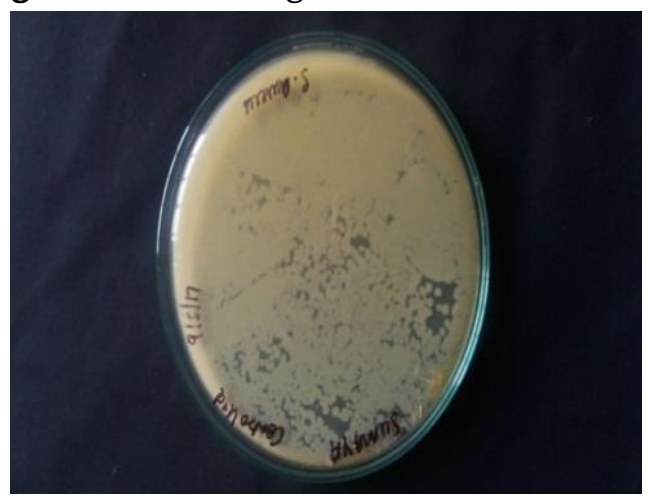

Fig.7: Cultured Plate

Table - 2 Different con. and inhibition zone

\begin{tabular}{|c|c|}
\hline $\begin{array}{c}\text { Concentrations of } P . \\
\text { hysterophorus. extract } \\
(\mathrm{mg} / \mathrm{ml})\end{array}$ & $\begin{array}{c}\text { Zone of Inhibition (mm) } \\
\text { in Staphylococcus aureus }\end{array}$ \\
\hline 100 & 7.33 \\
\hline 75 & 6.0 \\
\hline 50 & 5.33 \\
\hline 25 & 2.66 \\
\hline Controlled & 0.0 \\
\hline
\end{tabular}

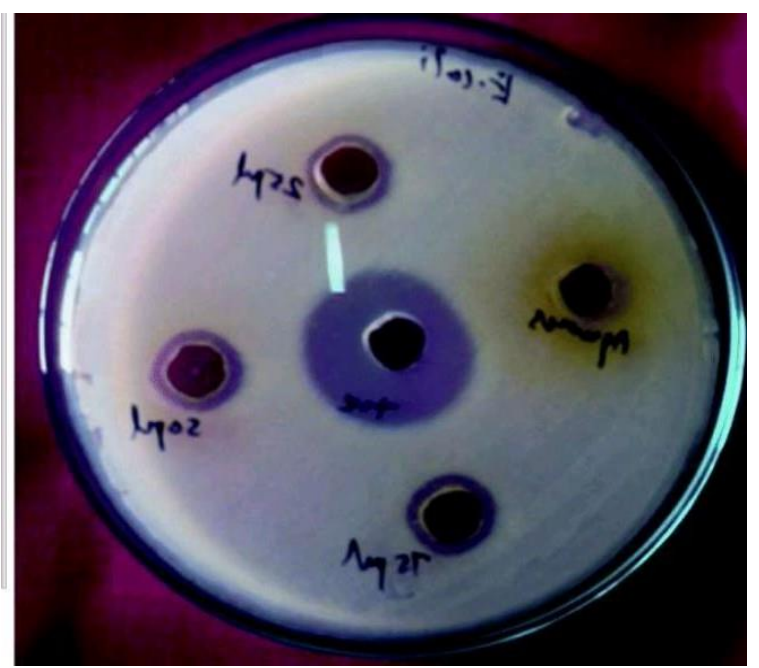

Fig. 8: Inhibition zone of different con.

\section{RESULT AND DISCUSSION}

Results of the antibacterial screening of different concentrations of the extracts on the test isolates are shown in Table 2. The results show that the increase in concentration of the extract increased the zones of growth inhibition of the bacteria (Fig.8). The assessment of the antibacterial activity was based on the measurement of diameter zone of inhibition (mm) that formed around the hole made by the borer filled with the extract. Maximum inhibition zone was recorded at $100 \mathrm{mg} / \mathrm{ml}$ and the minimum inhibition zone at $25 \mathrm{mg} / \mathrm{ml}$ in both the bacteria for all the extracts and controlled petriplates showed no zone of Inhibition (Table-2; Fig 8).This proved that the extract is effective against microbes.

In this study, the results obtained indicated that the methanolic extract of the plants inhibited the growth of the two test bacteria. This therefore, showed that the extract contained substances that can inhibit the growth of the selected bacteria. Other workers have also shown that extracts of plants inhibit the growth of various microorganisms at different concentrations (A kujobi et al. 2008; Horbone. 1998). From the review of $A$. conyzoides by Okawulhie (2013) a wide range of chemical compounds including alkaloids, 
flavonoids, chromenes, benzofurans and terpenoids have been isolated. Phytochemical screening of extracts of P. hysterophorus L.showed the presence of alkaloids, saponins, flavonoids, tannin, steroids and cardiac glycosides.So, it may be due to the presence of these chemical compounds and substances that the plant extracts can inhibit the growth of the bacteria.

\section{REFERENCES}

[1]. Aqil, F. and I. Ahmad, (2003). Broad-spectrum antibacterial and antifungal properties of certain traditionally used Indian medicinal plants. World J. Microbiol. Biotechnol.,19:653657.

[2]. Adejara, O.Y.,Oduyebo, (2013). In-vitro antifungal effect of Garcinia kola and garlic (Alliums sativum) on vaginal isolates of candida. African Journal of Clinical and Experimental Microbiology 14(3)DOI:10.4314/ajcem.v14i3.4

[3]. Anjoo Kamboj, Ajay Kumar Saluja (2008). “Ageratum conyzoides L.: A review on its phytochemical and pharmacological profile.l International journal of green pharmacy; 4(3): 1998- 4103.

[4]. Ashwini S and Girish K (2014). Phytochemical screening and antibacterial activity of methanolic leaf extract of Coleus aromaticus benth. International Journal of Research in Pharmaceutical Sciences. 5, (4),270-274.

[5]. Chah KF, Eze CA, Emuelosi CE, Esimone CO (2006). - Antibacterial and wound healing properties of methanolic extracts of some Nigerian medicinal plants.l J. Ethnopharmacol; 1019: 1619-1621.

[6]. Ghaleb Adwan and Mohammad Mhanna (2008): Synergistic Effects of Plant Extracts and Antibiotics on Staphylococcus aureus Strains Isolated from Clinical Specimens : Middle-East Journal of Scientific Research 3 (3): 134-139,
[7]. Harborne, J.B. (1998). - Phytochemical Methods: A Guide to Modern Techniques of Plant Analysis.ll (3rd Edn) chapman and Hall:London; 302.

[8]. Maher Boukhris,Monique S. J. Simmonds,Sami Sayadi,Mohamed Bouaziz (2013).Chemical Composition and Biological Activities of Polar Extracts and Essential Oil of Rose-scented Geranium, Pelargonium graveolens Phytotherapy Research Volume27, Issue8 Pages 1206-1213 https://doi.org/10.1002/ptr.4853

[9]. Mounyr Balouiri, Moulay Sadiki , Saad Koraichi Ibnsouda (2016), Methods for in vitro evaluating antimicrobial activity: A review J Pharm Anal 6(2):71-79. doi: 10.1016/j.jpha.2015.11.005.

[10]. Muzafar Sheikh, Abdul Rashid Malik, M. K. Meghavanshi, Irshad Mahmood (2012). Studies on Some Plant Extracts for Their Antimicrobial Potential against Certain Pathogenic Microorganisms.| American Journal of Plant Sciences; 3:209-213.

[11]. Okwulehie, Ikechukwu Cyriacus and Akanwa, $\quad$ Franklin Eberechukwu (2013). Antimicrobial Activity of Ethanol Extract of Four Indigenous Plants From South Eastern Nigeria.l ARPN Journal of Science and Technology; 3(4) : 2225-7217.

[12]. Ravi Kumar Gupta, Ravi Kant Upadhyay NCCLS (1993) Performance Standard for Antimicrobial Disc Susceptibility Tests. P.A. Publication M2-A5. USA.Journal of Biosciences and Medicines, Vol.4 No.8, July 25, 2016

[13]. Richerd c. Mulligan (1993), the basic science of gene therepy. Science vol.260 pp 926-932.

[14]. Sumitra Chanda, Kalpna Rakholiya, Rathish Nair (2011). Antimicrobial Activity of Terminalia catappa L. Leaf Extracts against Some Clinically Important Pathogenic Microbial Strains. Chinese Medicine Vol.2(4) DOI: $10.4236 / \mathrm{cm} .2011 .24027$ 
[15]. Timothy J Tracey , Frederik J Steyn , Ernst J Wolvetang , Shyuan T Ngo (2018). Neuronal Lipid Metabolism: Multiple Pathways Driving Functional Outcomes in Health and Disease Mol Neurosciense. DOI: 10.3389/fnmol.2018.00010

[16]. Veena B K and Shivani M (2012). Biological utilities of Parthenium hysterophorus. Journal of Applied and Natural Science, 4(1), 137-143.

[17]. V.Singh- A.Lehri- N.Singh (2018). Assessment and comparison of phytoremediation potential of selected plant species against endosulfan International Journal of Environmental Science and Technology https://doi.org/10.1007/s13762018-1880-y

\section{Cite this article as :}

Versha Upadhyay, "Antipathetic Effect of Parthenium Hysterophorous on Staphylococcus Aureus", International Journal of Scientific Research in Science and Technology (IJSRST), Online ISSN : 2395-602X, Print ISSN : 2395-6011, Volume 8 Issue 6, pp. 371-379, November-December 2021. Available at doi : https://doi.org/10.32628/IJSRST218619

Journal URL : https://ijsrst.com/IJSRST218619 